\title{
MOLECULAR GENETIC INVESTIGATIONS ON BALANTIDIUM CTENOPHARYNGODONI CHEN, 1955, A PARASITE OF THE GRASS CARP (CTENOPHARYNGODON IDELLA)
}

\author{
Szilvia MARTON ${ }^{1 *}$, Krisztián BÁNYAI ${ }^{1}$, Barbara FoRRÓ ${ }^{1}$, György LENGYEL ${ }^{2}$, \\ Csaba SzÉKELY ${ }^{1}$, Ádám VARGA ${ }^{1}$ and Kálmán MOLNÁR ${ }^{1}$ \\ ${ }^{1}$ Institute for Veterinary Medical Research, Centre for Agricultural Research, \\ Hungarian Academy of Sciences, P.O. Box 18, H-1581 Budapest, Hungary; \\ ${ }^{2}$ Military Medical Centre, Hungarian Defence Forces, Budapest, Hungary
}

(Received 7 January 2016; accepted 4 May 2016)

Balantidium ctenopharyngodoni is a common ciliate in Hungary, infecting the hindgut of grass carp (Ctenopharyngodon idella), a cyprinid fish of Chinese origin. Although data have already been presented on its occasional pathogenic effect on the endothelium of the host, generally it is a harmless inhabitant of the gut. Phylogenetic analysis of the 18S rDNA and ITS fragments of this protozoan proved that it is in the closest phylogenetic relationship with endocommensalist and symbiont ciliates of mammals feeding on large volumes of green forage, in a similar way as Balantidium spp. known from algae-eating marine fishes.

Key words: Protozoa, grass carp, intestinal infection, systematics, DNA, molecular phylogeny

Balantidium spp. are common and frequent intestinal protozoa of different vertebrate animals ranging from fish to mammals (Fauré-Fremiet, 1955). Their most common representative is Balantidium coli Malmstein, a protozoan infecting the gut of humans, apes and pigs (Mehlhorn, 1988). Besides mammals and birds, numerous balantidia are known to occur in poikilothermic animals, e.g. Balantidium entozoon Claparède and Lachmann (the type species of the genus), B. duodeni Stein and B. honghuensis Li in frogs (Grim and Buonanno, 2009; Li et al., 2013; Chistyakova et al., 2014). A well-known species from fish is $B$. ctenopharyngodoni Chen, the parasite of grass carp (Ctenopharyngodon idella) (Chen, 1955). This species was first found in Europe by Musselius (1967) and Molnár and Reinhardt (1978) in imported and colonised grass carp. Further species from freshwater fishes, such as B. polyvacuolum from yellowfin (Xenocypris argentea) and B. barbi from Aral barbel (Barbus brachycephalus), were described by Li (1963) and Dogiel and Bychowsky (1934), respectively. Balantidium infection seems to be more common in marine fishes (Diamant and Wilbert, 1985; Grim, 1985, 1992, 1993; Zhao and Ma, 1992). Balantidia repro-

*Corresponding author; E-mail: szilvia.marton@agrar.mta.hu 
duce by repeated transverse binary fissions, but trophozoites may also encyst after being passed in the faeces. Balantidia are generally regarded as commensalists or symbionts, but Mehlhorn (1988) pointed out that these protists could act as pathogens by causing diarrhoea and ulcers in the gut. Particularly extensive changes appearing in diseases characterise the intestinal Balantidium infection of apes (Isidoro et al., 2013). Furthermore, Balantidium-associated inflammation and ulcers in the intestinal wall were described from Hungarian specimens of grass carp by Molnár and Reinhardt (1978).

Just like for other protists, determination of the host species and morphology is insufficient for species differentiation within the genus Balantidium, and genetic identification is also recommended. The genomic region encoding the small subunit rRNA is the most frequently used genetic marker for this purpose. Molecular biological studies have concerned mostly B. coli (Nilles-Bije and Rivera, 2010; Ponce-Gordo et al., 2011; Hassell et al., 2013; Chistyakova et al., 2014; Li et al., 2014). These studies have tried to detect the genetic diversity and clarify the phylogeny of Balantidium and Balantidium-like ciliates using this genomic region. Thus far, relatively few small subunit rRNA sequences have been determined for different Balantidium species originating from poikilothermic animals. In particular, at present only one $18 \mathrm{~S}$ rRNA sequence represents the 19 known Balantidium species of fish origin (Li et al., 2013, 2014).

\section{Materials and methods}

The fish material was an 80-cm-long, four-year-old grass carp (Ctenopharyngodon idella) harvested in Lake Balaton in May 2014 and sent to the laboratory for routine health examination. When examining the digestive tract, thousands of balantidia were observed in the hindgut of the fish. For further study of the location of these protists, a part of the hindgut was fixed in $10 \%$ formalin, embedded in paraffin wax, cut to 4-5 $\mu \mathrm{m}$ thick sections, and stained with haematoxylin and eosin. Protozoans were located free in the faeces. A gram of faeces was placed into a Petri dish filled with water. A part of the Balantidium specimens left the faeces, and about one hundred specimens could be collected without apparent contamination. After centrifugation the excess water was changed three times, and protozoans were fixed in $70 \%$ ethanol for molecular examination.

The DNA was extracted using the DNeasy Blood and Tissue kit (Qiagen) according to the manufacturer's recommendations.

For species identification, 18S rDNA specific PCRs were carried out using Erib1-Erib10 (Barta et al., 1997) and BD-BR (Ponce-Gordo et al., 2008) primer pairs. The reaction volume was $25 \mu \mathrm{L}$ and it contained $2 \mu \mathrm{L}$ DNA, $1 \cdot \times$ Dream Taq PCR buffer (Thermo Scientific), $2.5 \mathrm{mM} \mathrm{MgCl}_{2}, 300 \mathrm{mM}$ dNTP mix (Thermo 
Scientific), $400 \mu \mathrm{M}$ of each primer, and $1 \mathrm{U}$ of Dream Taq DNA Polymerase (Thermo Scientific). The amplification conditions were as follow: an initial denaturation step of $5 \mathrm{~min}$ at $95^{\circ} \mathrm{C}$ was followed by 40 cycles at $95^{\circ} \mathrm{C}$ for $30 \mathrm{sec}$, $50{ }^{\circ} \mathrm{C}$ for $30 \mathrm{sec}, 72{ }^{\circ} \mathrm{C}$ for $60 \mathrm{sec}$, and terminated with a final extension step at $72{ }^{\circ} \mathrm{C}$ for $5 \mathrm{~min}$.

We also amplified the ITS1-5,8S-ITS2 region using the primers B5D-B5R (Ponce-Gordo et al., 2008) and a fragment of the 28S rDNA with the primer pair LSU 1F-LSU 998R (Molnár et al., 2012). The reactions were carried out in a total volume of $25 \mu \mathrm{L}$. The proportions of the components and the thermal profile were as described above with $50{ }^{\circ} \mathrm{C}$ (ITS1-5,8S-ITS2 region) or $45^{\circ} \mathrm{C}(28 \mathrm{~S}$ rDNA region) annealing temperature.

The PCR products were run on $1 \%$ agarose gel stained with GelRed (Biotium) in TBE buffer. The obtained fragments were excised and extracted from the gel using Gel/PCR DNA Fragments Extraction Kit (Geneaid), and were directly sequenced. Besides the aforementioned PCR primers, for the sequencing of the 18S rDNA BID, BIDR, BIR (Ponce-Gordo et al., 2008) and for the 28S rDNA region LSU 274F (Molnár et al., 2012) primers were additionally applied. Sequencing reactions were prepared with BigDye Terminator v1.1 Cycle Sequencing Kit (Life Technologies), and chromatograms were generated on an automated sequence analyser (ABI Prism 3100).

For the phylogenetic analysis the obtained 18S rDNA and ITS fragments were aligned with homologue sequences of ciliates available in GenBank using the MultAlin program (Corpet, 1988) and edited manually in GeneDoc (Nicholas et al., 1997). The analysis was performed using the MEGA 6 software (Tamura et al., 2013). Phylogenetic trees were constructed by the maximum-likelihood statistical method with GTR $+\mathrm{G}+\mathrm{I}$ substitution model, and bootstrap analysis was performed with 500 replications.

\section{Results}

Morphological observation suggested that the abundant protozoon in the examined grass carp intestine was $B$. ctenopharyngodoni. The histological picture, which corresponded to that found by Molnár and Reinhardt (1978), supported the diagnosis; this showed a heavy infection in the intestine, although without apparent epithelial damage (Fig. 1). Subsequent DNA sequencing confirmed B. ctenopharyngodoni infection of the grass carp examined. The amplified and sequenced 1635-bp-long fragment of the small subunit ribosomal RNA gene (KU170970) was $99.8 \%$ similar to the partial sequence of B. ctenopharyngodoni 18S rDNA (GU480804) sequenced in China (Li et al., 2014). Another 384-bp fragment encoding the ITS1-5,8S-ITS2 region (KU170972) could also be sequenced, and this region resembled Balantidium coli (HF545448) with $86.4 \%$ identity. We also successfully sequenced a 792-bp fragment of the $28 \mathrm{~S}$ rDNA 
(KU170971) of the parasite, which showed 96.9\% identity to the sequence of the ciliate Spathidium amphoriforme (AF223570).

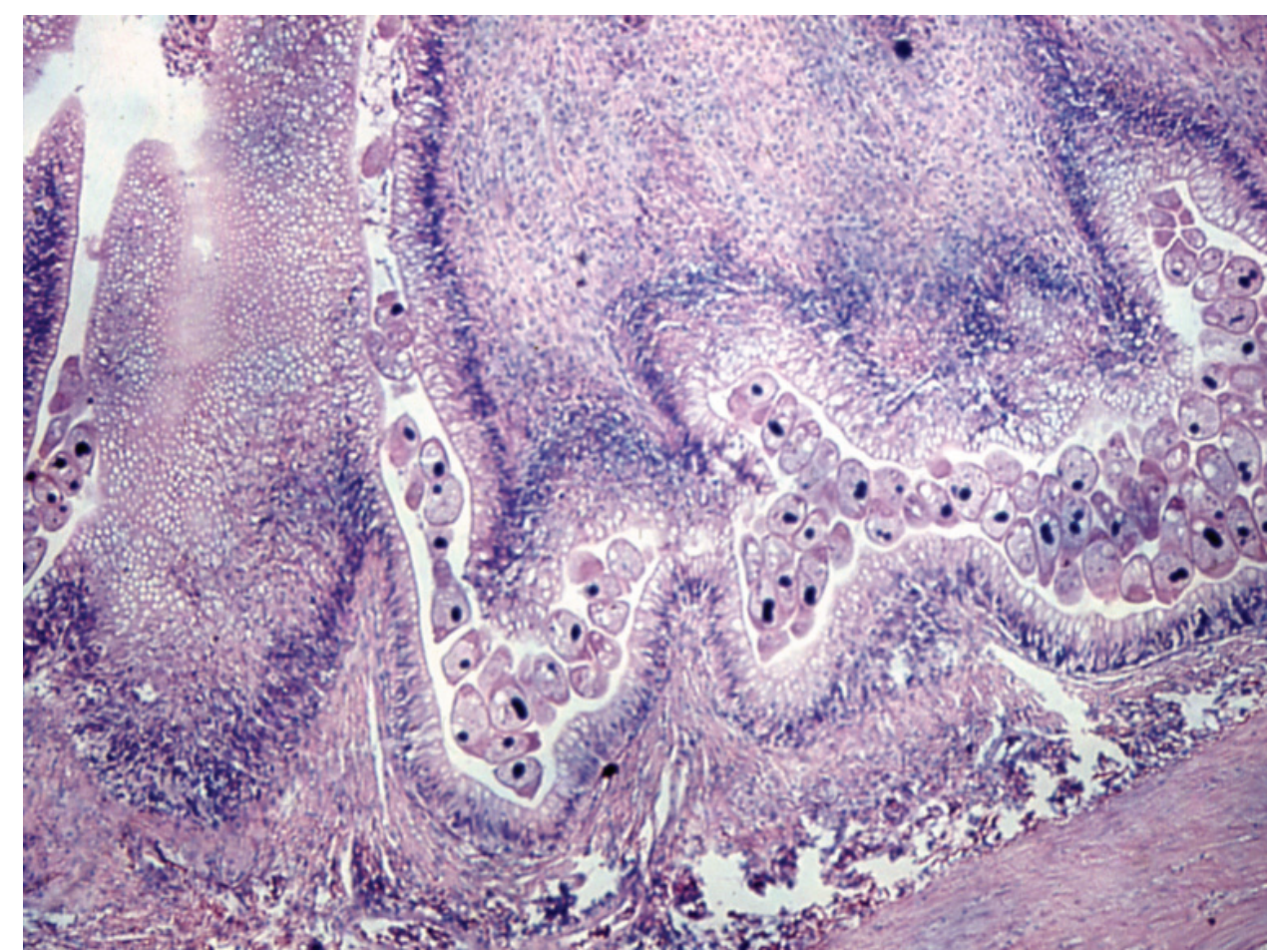

Fig. 1. Heavy Balantidium ctenopharyngodoni infection in the hindgut of a four-year-old grass carp. Haematoxylin and eosin (HE) staining, $\times 1000$

Molecular studies (Fig. 2) revealed that the DNA structure of this protozoan shows great divergence from the common holotrich protozoans (Ichthyophthirius multifiliis, Tetrahymena pyriformis, Chilodonella cyprini) infecting fishes but has a great resemblance to other Balantidium spp. occurring in the gut of mammals which feed mostly on vegetation. The similarity was relatively high to holotrich protozoa (Diplodinium, Epidinium, Isotricha, Dasytricha spp.) constituting the fauna in the rumen. Moreover, it was a surprise that the highest similarity was found to intestinal ciliates (Polycosta, Bitricha and Bandia spp.) occurring in the gut of marsupials. It should also be remarked that Balantidium entozoon, a parasite of the poikilothermal Rana esculenta, showed lower similarity $(92.3 \%)$ to B. ctenopharyngodoni than the Balantidium, Neobalantidium and Buxtonella spp. of warm-blooded animals. 


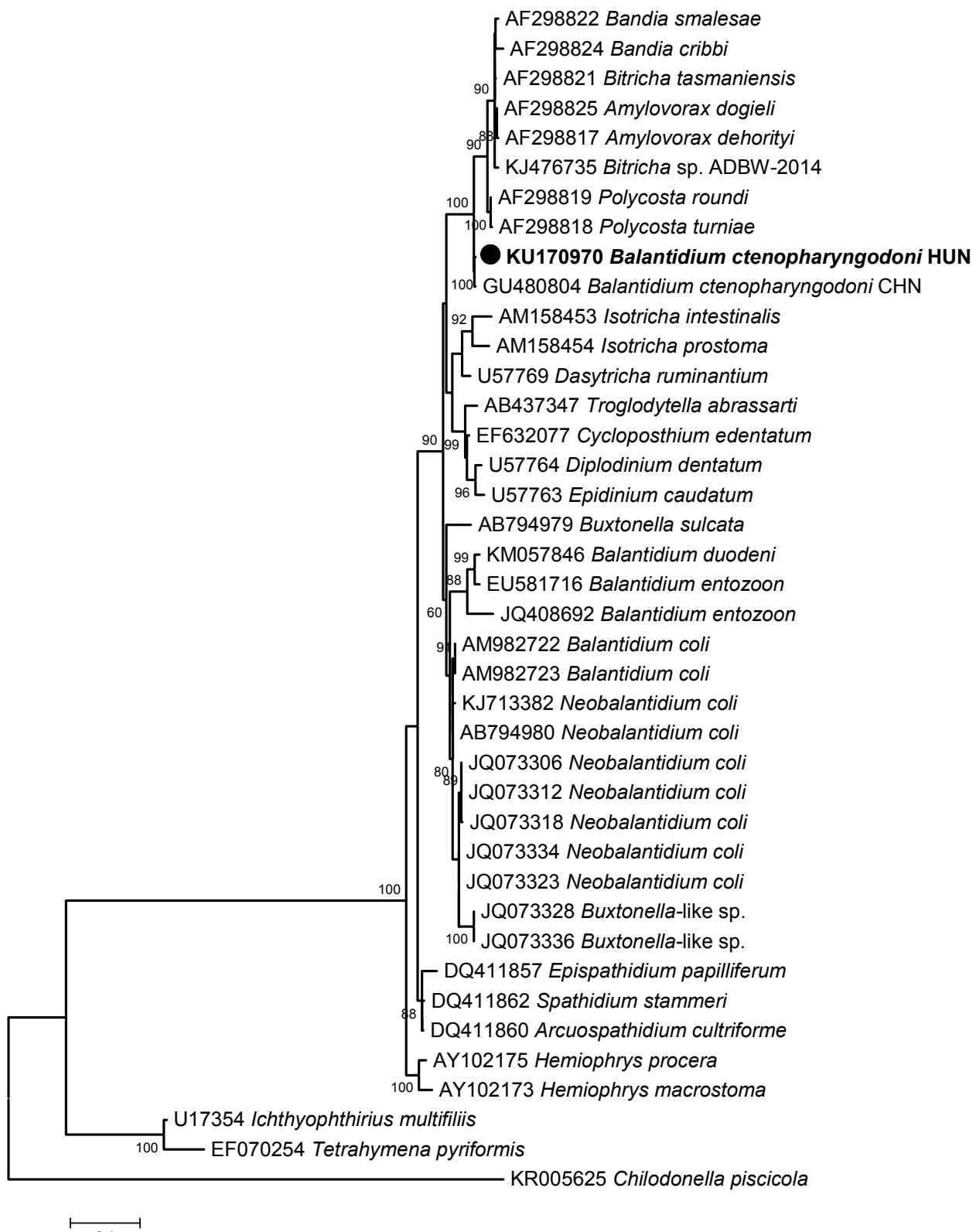

Fig. 2. Maximum-likelihood tree generated from the $18 \mathrm{~S}$ rDNA genomic region of Balantidium ctenopharyngodoni and other related ciliates. Bootstrap values greater than $60 \%$ are shown at the branch nodes 


\section{Discussion}

Since Molnár and Reinhardt (1978) described a disease caused by $B$. ctenopharyngodoni in grass carp, this protist has been regularly found in the gut of Hungarian grass carp specimens older than two years, although no additional serious veterinary issues emerged over time. The parasite was found neither in other introduced Chinese major carp species nor in local Hungarian fishes (Molnár, 1979; Molnár, unpublished data). Recently, the 18S rRNA sequence of $B$. ctenopharyngodoni from China has been published (Li et al., 2014), and sequencing results obtained in our laboratory confirmed the presence of this protozoan in Hungary.

The close resemblance of the DNA structure to that of endocommensalist or symbiont ciliates of the rumen indicates that under normal conditions $B$. ctenopharyngodoni may be a commensalist organism in the gut of grass carp and probably plays a similar role as Balantidium spp. in mammals feeding on largevolume green forage. Similarly, Balantidium spp. may colonise only fishes (of either freshwater or marine origin) which feed predominantly on aquatic vegetation. Thus, it is not surprising that this protozoan has never been found in fingerlings and young specimens of grass carp, the diet of which consists mainly of zooplankton. In agreement with these findings, B. ctenopharyngodoni has never been detected in young grass carp during routine parasite surveillance over the past 35 years (Molnár, unpublished observation).

Besides $B$. ctenopharyngodoni, two additional Balantidium spp. are known from freshwater fishes (i.e. B. polyvacuolum and B. barbi), and both species live in algae-eating fishes (such as Xenocypris and Barbus spp.) (Li, 1963; Shulman and Jankovski, 1984). It is still not known whether these protozoans are harmless commensalists of the gut or endosymbionts similar to those of marine species $(B$. sigani, B. prionurium, B. jocularum, B. zebrascopi), which live in the gut of different surgeon fishes and rabbitfishes (Prionurus, Zebrasoma, Naso and Siganus spp.) feeding on algae (Diamant and Wilbert, 1985; Grim, 1985, 1993). For ciliates participating in the decomposition of cellulose in the rumen the symbiotic effect seems to be proven (Moon-van der Staay et al., 2014), although Balantidium spp. should be rather regarded as harmless commensalists. There are, however, reports indicating that in mammals, due to unfavourable feeding conditions or bacterial contamination, the endocommensalist Balantidium spp. (e.g. B. coli) may become pathogenic and cause severe diseases. Süveges (2004) described that $B$. coli invasion was promoted by circovirus infection in pigs, while Isidoro et al. (2013) reported severe haemorrhagic-necrotising colitis associated with Campylobacter jejuni and Balantidium coli in a captive gorilla. In view of these recent findings it cannot be excluded that the severe damage described by Molnár and Reinhardt (1978) in the gut of grass carp in association with $B$. ctenopharyngodoni was triggered by viral or bacterial co-infection. This hy- 
pothesis needs further investigation in order to understand the pathogenesis associated with Balantidium infection and to design and implement adequate preventive and control measures.

SSU rRNA sequences are widely used in taxonomic studies at the genus level and in species identification. We expected that determination of the ITS and the 28S rRNA coding genomic regions would permit further insight into the genetics of B. ctenopharyngodoni. Among closely related species the sequences of ITS regions of the ribosomal RNA are commonly utilised in population genetic studies to differentiate various parasite species (Bachellerie and Qu, 1993; Wright, 1999). Within Balantidium spp. the ITS1-5.8S-ITS2 region was used to reveal the molecular diversity at the subspecies level and, as a result, two different genotypes could be distinguished among the specimens studied so far (Ponce-Gordo et al., 2008). In a subsequent study, Ponce-Gordo et al. (2011) performed genetic analysis of the ITS regions of single Balantidium coli cells. In these analyses five additional sequence types of the aforementioned two genotypes were distinguished and, interestingly, the co-existence of several sequence types in a single cell was also observed. Similar conclusions were drawn by Le Blancq et al. (1997) when studying different ITS genotypes in the genome of cryptosporidia. These data indicate that the ITS regions may not serve as a universal genetic marker in protist taxonomy and may have limited value in detecting intraspecific genetic variability in some parasites. Unfortunately, until the submission of the present paper no additional Balantidium-specific sequence information had been released in public DNA databases. Thus, the question whether these genomic regions may be suitable for assessing genetic variation within B. ctenopharyngodoni has remained open.

\section{Acknowledgements}

This project was supported by the Hungarian Scientific Research Fund (OTKA K100132) and the Momentum Program awarded by the Hungarian Academy of Sciences.

\section{References}

Bachellerie, J. P. and Qu, L. H. (1993): Ribosomal RNA probes for detection and identification of species. Methods Mol. Biol. 21, 249-263.

Barta, J. R., Martin, D. S., Liberator, P. A., Dashkevicz, M., Anderson, J. W., Feighner, S. D., Elbrecht, A., Perkins-Barrow, A., Jenkins, M. C., Danforth, H. D., Ruff, M. D. and ProfousJuchelka, H. (1997): Phylogenetic relationships among eight Eimeria species infecting domestic fowl inferred using complete small subunit ribosomal DNA sequences. J. Parasitol. 83, 262-271.

Chen, C. L. (1955): The protozoan parasites from four species of Chinese pond fishes: Ctenopharyngodon idellus, Mylopharyngodon piceus, Aristhicthys nobillis and Hypophthalmich- 
thys molitrix. The protozoan parasites of Ctenopharyngodon idellus. Acta Hydrobiol. Sin. $1,123-164$.

Chistyakova, L. V., Kostygov, A. Y., Kornilova, O. A. and Yurchenko, V. (2014): Reisolation and redescription of Balantidium duodeni Stein, 1867 (Litostomatea, Trichostomatia). Parasitol. Res. 113, 4207-4215.

Corpet, F. (1988): Multiple sequence alignment with hierarchical clustering. Nucl. Acids Res. 16, 10881-10890.

Diamant, A. and Wilbert, N. (1985): Balantidium sigani sp. nov., a trichostome ciliate from Red Sea rabbitfish (Pisces, Siganidae). Arch. Protistenkunde 129, 13-17.

Dogiel, V. A. and Bychowsky, B. E. (1934): Parasite fauna of fish in Aral Sea [in Russian]. Parasitol. Sborn. ZIN AN SSSR 4, 241-246.

Fauré-Fremiet, E. (1955): La position systematique du genre Balantidium. J. Protozool. 2, 54-58.

Grim, J. N. (1985): Balantidium prionurium n. sp., symbiont in the intestine of the surgeonfish, Prionurus punctatus. J. Protozool. 32, 587-588.

Grim, J. N. (1992): Descriptions of two sympatric and phylogenetically diverse ciliated Protozoa, Balantidium zebrascopi n. sp. and Paracichlidotherus leeuwenhoeki n. gen., n. sp., symbionts in the intestines of the surgeonfish, Zebrasoma scopas. Trans. Amer. Microsc. Soc. 111, 149-157.

Grim, J. N. (1993): Description of somatic kinetics and vestibular organization of Balantidium jocularum sp. n. and possible taxonomic implications for the Class Litostomatea and the Genus Balantidium. Acta Protozool. 32, 37-45.

Grim, J. N. and Buonanno, F. (2009): A re-description of the ciliate genus and type species, Balantidium entozoon. Eur. J. Protistol. 45, 174-182.

Hassell, J. M., Blake Darner, P., Cranfield, M. R., Ramer, J., Hogan, J. N., Noheli, J. B., Waters, M. and Hermosilla, C. (2013): Occurrence and molecular analysis of Balantidium coli in mountain gorilla (Gorilla beringei beringei) in the Volcanoes National Park, Rwanda. J. Wildl. Dis. 49, 1063-1065.

Isidoro, M., Martínez, J. and Ramis, A. (2013): Haemorrhagic-necrotizing colitis associated with Campylobacter jejuni and Balantidium coli in a zoo gorilla. J. Comp. Pathol. 148, 87.

Le Blancq, S. M., Khramtsov, N. V., Zamani, F., Upton, S. J. and Wu, T. W. (1997): Ribosomal RNA gene organization in Cryptosporidium parvum. Mol. Biochem. Parasitol. 90, 463-478.

Li, L. (1963): Studies on a new ciliate, Balantidium polyvacuolum sp. nov., from the intestine of fishes. Acta Hydrobiol. Sin. 1, 81-97.

Li, M., Li, W., Zhang, L. and Wang, C. (2013): Balantidium honghuensis n. sp. (Ciliophora: Trichostomatidae) from the rectum of Rana nigromaculata and $R$. limnocharis from Honghu Lake, China. Korean J. Parasitol. 51, 427-431.

Li, M., Ponce-Gordo, F., Grim, J. N., Wang, C. and Nilsen, F. (2014): New insights into the molecular phylogeny of Balantidium (Ciliophora, Vetibuliferida) based on the analysis of new sequences of species from fish hosts. Parasitol. Res. 113, 4327-4333.

Mehlhorn, H. (1988): Parasitology in Focus. Springer Verlag, Berlin. 924 pp.

Molnár, K. (1979): Protozoan parasites of fish species indigenous in Hungary. Parasit. Hung. 12, $5-8$.

Molnár, K. and Reinhardt, M. (1978): Intestinal lesions in grasscarp Ctenopharyngodon idella (Valenciennes) infected with Balantidium ctenopharyngodonis Chen. J. Fish Dis. 1, 151-156.

Molnár, K., Ostoros, Gy., Dunams-Morel, D. and Rosenthal, B. M. (2012): Eimeria that infect fish are diverse and are related to, but distinct from, those that infect terrestrial vertebrates. Infect. Genet. Evol. 12, 1810-1815.

Moon-van der Staay, S. Y., van der Staay, G. W., Michalowski, T., Jouany, J-P., Pristas, P., Javorský, P., Kišidayová, S., Varadyova, Z., McEwan, N. R., Newbold, C. J., van Allen, T., de Graaf, R., Schmid, M., Huynen, M. A. and Hackstein, J. H. (2014): The symbiotic intestinal ciliates and the evolution of their hosts. Eur. J. Protistol. 50, 166-173. 
Musselius, V. A. (1967): Parasites and diseases of phytophagous fishes and their control [in Russian]. Publishing House KOLOS, Moscow. 83 pp.

Nicholas, K. B., Nicholas, H. B. Jr. and Deerfield, D. W. II (1997): GeneDoc: Analysis and visualization of genetic variation. EMBNEW NEWS 4, 14.

Nilles-Bije, M. L. and Rivera, W. L. (2010): Ultrastructural and molecular characterization of Balantidium coli isolated in the Philippines. Parasitol. Res. 106, 387-394.

Ponce-Gordo, F., Fonseca-Salamanca, F. and Martinez-Diaz, R. A. (2011): Genetic heterogeneity in internal transcribed spacer genes of Balantidium coli (Litostomatea, Ciliophora). Protist. 162, 774-794.

Ponce-Gordo, F., Jimenez-Ruiz, E. and Martínez-Díaz, R. A. (2008): Tentative identification of the species of Balantidium from ostriches (Struthio camelus) as Balantidium coli-like by analysis of polymorphic DNA. Vet. Parasitol. 157, 41-49.

Shulman, S. S. and Jankovski, A. V. (1984): Phylum Ciliates-Ciliophora Doflein, 1901. In: Shulman, S. S. (ed.) Parasitic Protozoa, Volume 1 in Bauer, O. N. (ed.) Key to Parasites of Freshwater Fishes of the USSR [in Russian]. Nauka, Leningrad. pp. 262-267.

Tamura, K., Stecher, G., Peterson, D., Filipski, A. and Kumar, S. (2013): MEGA6: molecular evolutionary genetics analysis version 6.0. Mol. Biol. Evol. 30, 2725-2729.

Süveges, T. (2004): Enteric lesions caused by Balantidium coli in weaned pigs infected with circovirus (PCV-2) [in Hungarian, with English abstract]. Magy. Allatorvosok 126, 664-669.

Wright, A. D. (1999): Analysis of intraspecific sequence variation among eight isolates of the rumen symbiont, Isotricha prostoma (Ciliophora), from two continents. J. Eukaryot. Microbiol. 46, 445-446.

Zhao, Y-J. and Ma, C-L. (1992): A new species of parasitic Balantidium from the freshwater fishes of China (Trichostomatida: Balantidiidae). Acta Zootax. Sin. 17, 1-5. 